Case Report

\title{
CONGENITAL MESOBLASTIC NEPHROMA IN A YOUNG BEAGLE DOG
}

\author{
Katsuhiko Yoshizawa, Yuji Oishi, Natsuyo Makino, Junya Suzuki, \\ Masahiro Matsumoto, Yoshifumi Fukuhara, Shiro Fujihira, \\ and Toshiyuki Fujii \\ Department of Pathology and General Toxicology, Toxicology Research Laboratories, Fujisawa \\ Pharmaceutical Co., Ltd.
}

\begin{abstract}
A 10-month-old male beagle dog had a congenital tumor in the right kidney. Histopathologically, the tumor was characterized by fingerlike extensions projecting into the adjacent normal tissue, and often entrapping the normal glomerulo-tubular structure. The tumor was composed of spindle cells arranged in an interlacing fascicular pattern with some collagen fibers. Ultrastructurally, the tumor cells had long projections on the surface, rarely in contact with the junctional structures among the neighboring cells, and formed thin discontinuous basement membranes at the cell ends. Immunohistochemically, the tumor cells showed positive reactions with vimentin and S-100 protein antisera, and some weak reactions with actin, desmin, or myoglobin, but no reactions with cytokeratin.

This present tumor should be diagnosed as a congenital mesoblastic nephroma (CMN) on the basis of characteristic features in HE staining, other immunohistochemical reactions, and electromicroscopic findings, as well as the young age of the dog. (J Toxicol Pathol 9: 101 105, 1996)

Key words: Dog, Renal tumor, Congenital mesoblastic nephroma, Nephroblastoma, Spontaneous tumor
\end{abstract}

\section{Introduction}

Though spontaneous renal neoplasms in the dog are uncommon, renal tumors such as adenoma ${ }^{1,2}$, carcinoma ${ }^{1-3}$, nephroblastoma ${ }^{24}$, interstitial cell tumor $^{5}$, fibroma ${ }^{6}$, fibrosarcoma ${ }^{1,2}$, lipoma ${ }^{1}$, hemangioma ${ }^{1,2}$, hamartoma ${ }^{7}$, lymphosarcoma ${ }^{2}$, and papilloma ${ }^{2}$, or carcinoma of transitional cells ${ }^{1,2}$ have been reported. Recently, the extremely rare diagnoses which are congenital mesoblastic nephroma ${ }^{8}$ (CMN) and renal neurofibroma ${ }^{9}$ (NF) have also been reported in beagle dogs. $\mathrm{CMN}$ is one kind of benign nephroblastoma of early infancy in $\operatorname{dog}^{8}$, but detailed ultrastructural and immunohistochemical studies are lacking. Our description is the first instance of a spontaneous congenital mesoblastic nephroma in

義澤克彦 大石裕司 牧野奈津代 鉿木淳也 松本正博 福原良文 藤平司郎 藤井登志之

Accepted for publication : August 12, 1995

Mailing address : Katsuhiko Yoshizawa, Department of Pathology, Toxicology Research Laboratories, Fujisawa Pharmaceutical Co., Ltd. Kashima 2-1-6, Yodogawa, Osaka 532, Japan. young beagle dog, carried out with the aid of ultrastructural and immunohistochemical techniques.

\section{Materials and Methods}

The present neoplasm was found in a 10month-old male beagle dog among control animals of a subacute toxicity study for safety assessment in Toxicology Research Laboratories of Fujisawa Pharmaceutical Co., Ltd. The dog was purchased when six months old from Ichiyanagi Farm (Shizuoka, Japan) and had been vaccinated for several pathogens. In our facilities, the animal was housed alone in a stainless steel cage in an environment of $23 \pm 2^{\circ} \mathrm{C}$ temperature, $55 \pm 5 \%$ relative humidity and $12: 12 \mathrm{hr}$ light-dark sequence, and was fed a commercial dog diet (TC-1, Maruha Pet Food, Tokyo, Japan) of 300 g daily with free access to water. The animal was routinely observed for clinical signs twice a day and weighed once a week during the acclimation and the study periods. Routine hematological and bloodchemical examinations were done twice during the 
acclimation and once a week during the study. At the conclusion of the study, the animal was killed by bleeding from the cervical aorta under deep anesthesia. Detailed gross pathological examinatiton and weight of many organs including bilateral kidneys were performed. The organs were fixed in $10 \%$ phosphate buffered formalin, embedded in paraffin, sectioned, and stained with hematoxylin-eosin (HE) for routine histopathologic examinations. Additionally, renal lesions suggestive of abnormality were sectioned and stained with periodic acid-Schiff (PAS), azan, silver impregnation, and alcian blue $(\mathrm{pH}$ 2.5). Immunohistochemical examination was conducted with an avidin-biotin-complex immunoperoxidase method (ABC-Elite, Vector Laboratories, CA, USA) using anti-cow S-100 protein $(1: 200$ in dilution, Dako, Glostrup, Denmark), anti-swine vimentin (V9, $1: 50$, Dako), anti-human cytokeratin (MNF116, $1:$ 100, Dako), anti-human desmin (Clone 33, $1: 50$, Sanbio, Uden, Netherlands), anti human myoglobin $(1: 200$, Dako), and anti $\alpha$-smooth actin antibody (HHF35, 1 : 200, ENZO, New York, USA). For routine electron microscopy, some examples of renal lesions were further fixed in a $2.5 \%$ glutaraldehyde solution and postfixed in a $1 \%$ solution of osmium tetroxide, then dehydrated in ethanol and embedded in Epon812. Ultrathin sections was stained with uranyl acetate and lead citrate.

\section{Results}

No abnormalities were detected in clinical observations, bodyweight changes, hematology or bloodchemistry during the acclimation or the study periods. In gross appearance, a pale and slightly firm focus, $10 \times 10 \times 12 \mathrm{~mm}$ in size, in the right kidney was found. The longitudinal cut-surface showed a white to milky white focus extending from the cortex to the medulla with an ambiguous border (Fig. 1). The weights of both kidneys were within normal range. The other organs and tissues had no abnormalities in detailed gross and histo-pathological examinations except for the above mentioned right kidney.

Histopathologically, the tumor had infiltrated the adjacent renal tissue but there was no compression or formation of capsule at the border (Fig. 2). The normal glomerulus and tubules with few atrophic or cystic appearances were often entrapped by the tumor,

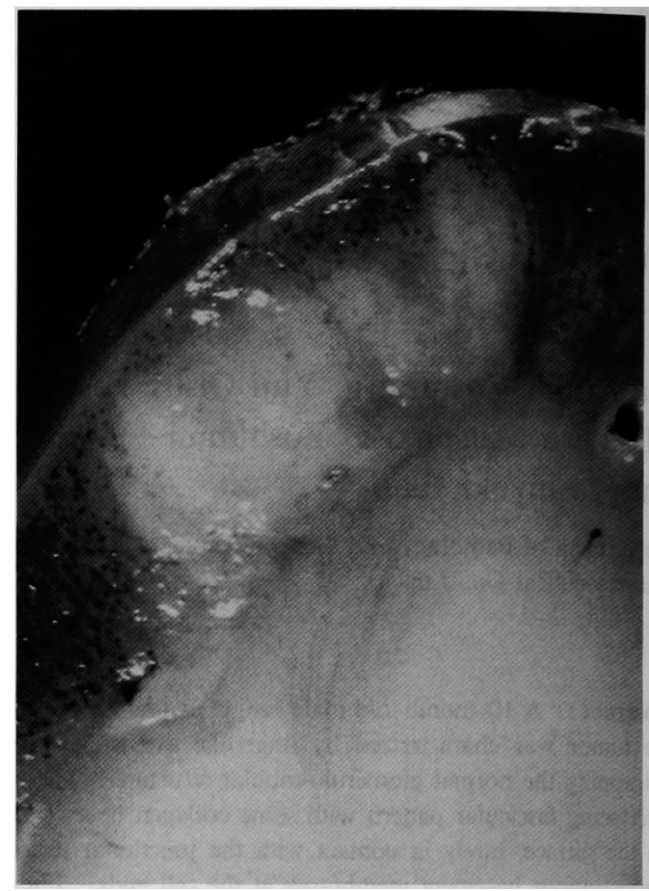

Fig. 1. Abnormal focus from cortex to medulla without circumscribed border or capsule in cut-surface of the right kidney.

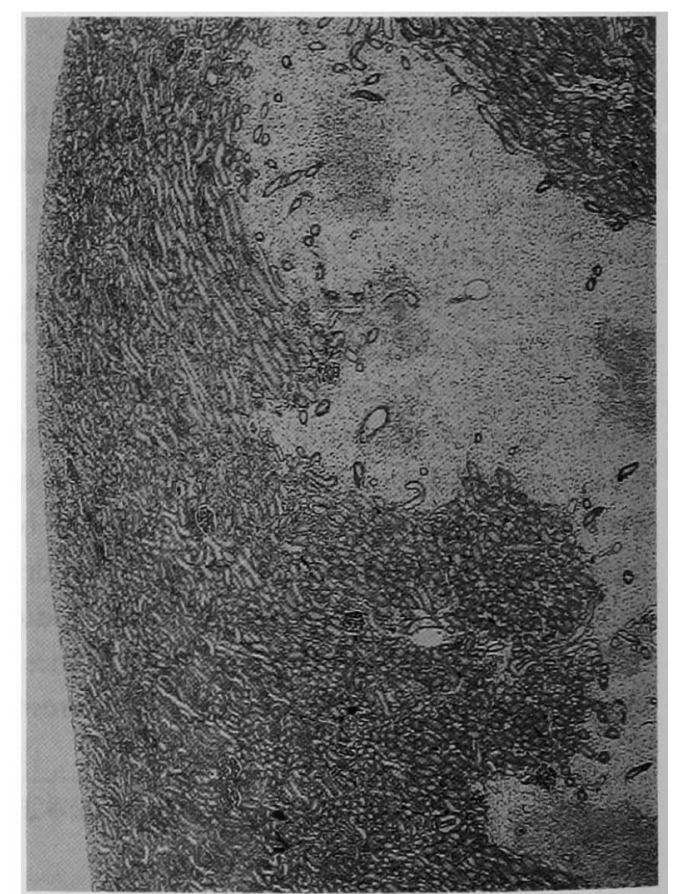

Fig. 2. Infiltrative pattern of tumor cells, which project into the adjecent normal structure like opening fingers, without compression. HE, $\times 23$. 


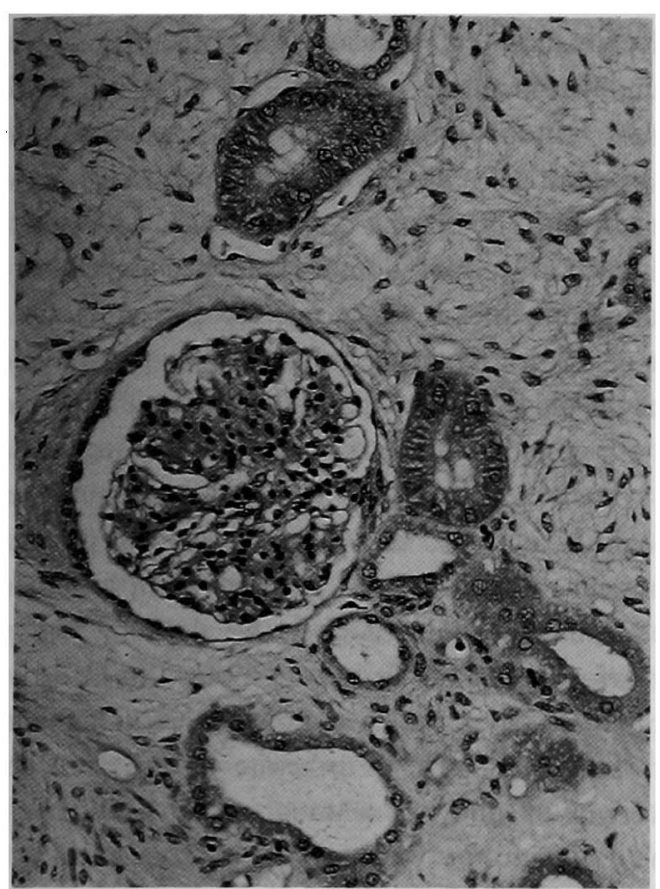

Fig. 3. Normal glomerulo-tubular structure in the myxomatous area of the tumor. HE, $\times 203$.

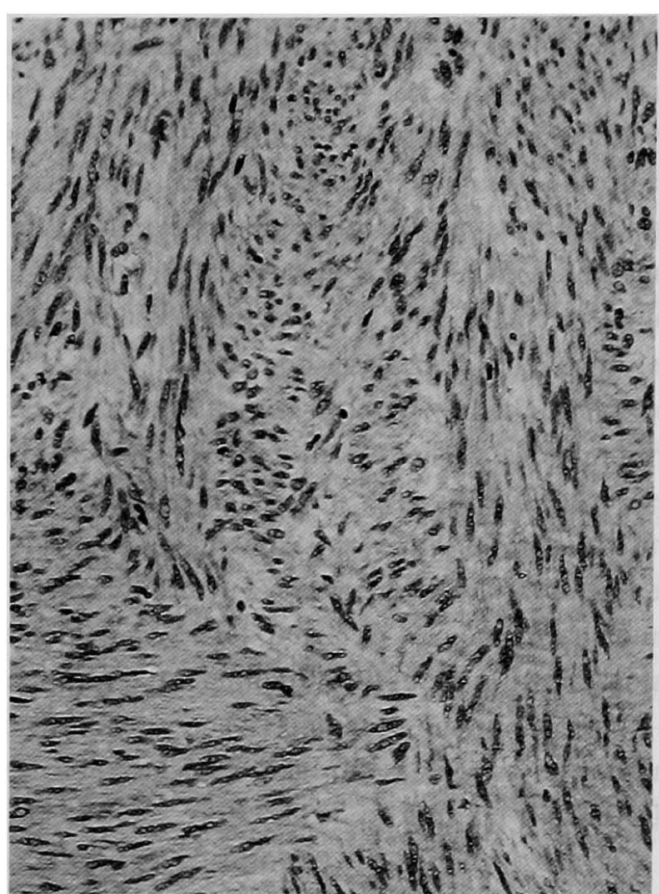

Fig. 4. The tumor is composed of long spindle-shaped cells arranging in an interlacing fascicular pattern. HE, $\times 203$.
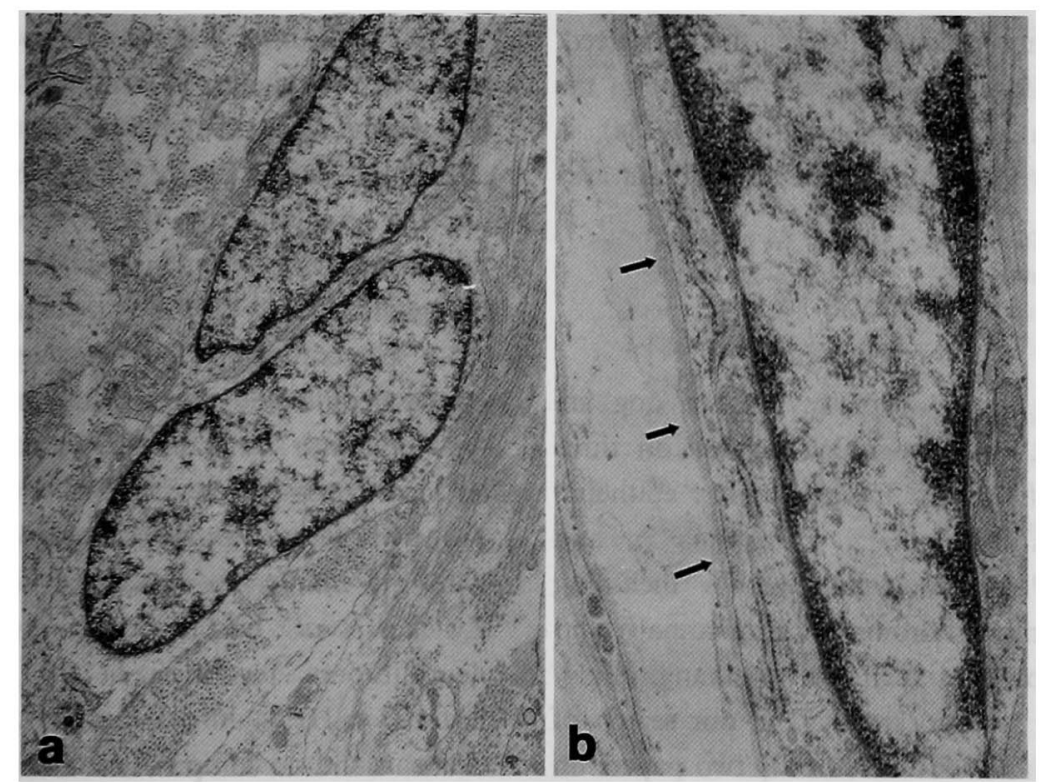

Fig. 5. Electron microscopical findings. (a) Tumor cells show spindle or rod-shaped nuclei and long cell processes, and produce a large amount of mature collagen fibers. $\times 9,600$. (b) Arrows show infrequent thin discontinuous basement membrane. $\times 28,800$. 
but the migration of the tumor cells to the structure was not seen (Fig. 3). In the loosely organized and myxomatous area (Fig. 3), the stroma was positive for alcian blue staining. The tumor was composed of long or short spindle cells, mostly arranged in a compact interlacing facicular pattern or presenting a wavy appearance (Fig. 4). The tumor cells had spindle-shaped or oval basophilic nuclei with a few nucleoli, eosinophilic cytoplasm with indistinct cellular border and some intercellular collagen, which was weakly positive for silver impregnation and PAS, and which was blue with azan staining. In all fields of the tumor, mitotic figures were scarce, and necrotic or hemorrhagic changes were not observed. Immunohistochemistry gave positive staining for vimentin and S- 100 protein in most tumor cells and weaker positive staining for actin, desmin, and myoglobin in some cells, but no reaction to cytokeratin.

Ultrastructurally, the tumor cells had spindle or rod-shaped nuclei (Fig. 5a) with occasional irregular nuclear membrane. A few mitochondria, long rough endoplasmic reticulum, free ribosome, microfilament, fatty droplets, and pinocytic vesicle were observed in the cytoplasm. The tumor cells had long projections on the surface, rarely contacted by junctional structures among neighboring cells and formed thin discontinuous basement membrane at the cells ends (Fig. 5b), but lamellar structures were not observed. While mature collagen fibers were prominent in the intracellular area of high cellularity (Fig. 5a), a myxomatous matrix was seen in the intracellular area of low cellularity.

\section{Discussion}

Spontaneous renal neoplasms in the dog are scarce. However, we have found reports on three general types of canine renal tumor: epithelial tumors such as adenoma $a^{1,2}$, carcinoma ${ }^{1-3}$, and nephroblastoma ${ }^{24}$; mesenchymal tumors including interstitial cell tumor ${ }^{5}$, fibroma ${ }^{6}$, fibrosarcoma ${ }^{1,2}$, and lipoma $^{1}$; and others such as hemangioma ${ }^{1,2}$, hamartoma ${ }^{7}$, and lymphosarcoma ${ }^{2}$, in our search of the literature to data. However, only two papers on renal tumors in laboratory beagle $\operatorname{dog}^{8,9}$ are available. Recently, a congenital mesoblastic nephroma $(\mathrm{CMN})^{\mathrm{s}}$ was reported for the first time in beagle dogs, as one kind of benign type of nephroblastoma of early infancy, but sufficient ultrastructural and immunohistochemical investigations were not performed. Histopathologically, our case possessed such characteristic features as showing infiltrative growth pattern into the normal adjacent renal tissue and the existence of normal glomero-tubular components in the tumor. Based on the microscopic similarities to the abovementioned canine $\mathrm{CMN}^{\mathrm{B}}$, the present lesion was diagnosed as a congenital mesoblastic nephroma. In our case, the tumor cells showed positive reaction to vimentin and S-100 protein in immunohistochemistry, and also showed elongated cell processes, poor junctional structure, poor basement membrane, and abundant collagen fibers by electromicroscopy. Therefore the tumor cells were thought to be derived from mesenchymal cells, and possibly from fibroblasts or schwann cells. Furthermore, the immunoreactivity of some of our tumor cells to actin, desmin, and myoglobin would be evidence of the myofibroblastic differentiation.

The present tumor in this case must be distinguished from such tumors as schwannoma, neurofibroma, fibroma, leiomyoma, and nephroblastoma (mesenchymal type). Our case was different from some cases of CMN in human ${ }^{10,11}$ and $\operatorname{dog}^{8}$ in point of immunoreactivity to anti-S- 100 protein as a marker of schwannoma and neurofibroma (NF) ${ }^{12}$. We could distinguish between this case and schwannoma in the absence of compression, encapsulation, interdigitation with renal elements, immunohistochemical reactivity except for anti-S- 100 protein, and lamellar structures. In this connection, most of the reported cases of human renal schwannoma ${ }^{13}$ were malignant and we found no literature about canine renal schwannoma in our investigation. Moreover, our case could be distinguished from NF, because this type of tumor generally shows compression of the adjacent tissue and some of the electromicroscopical properties of schwannoma, but no immunoreactivity with the markers of muscular tissue ${ }^{12}$. Formerly, Zwicker et al. ${ }^{9}$ had reported a case of canine renal neurofibroma, regardless of the same charactristic features in HE staining as interdigitation with renal elements and no compression of adjacent nephrons in $\mathrm{CMN}$ and our case. As the article did not describe the electromicroscopical and immunohistochemical analysis except $\mathrm{S}-100$ protein, more detailed evidence would be needed to make a definitive diagnosis of 
neurofibroma, and we dare say this case of CMN would hold true for our foregoing discussion. In addition to the aforesaid description, our case would be distinguishable from leiomyoma and fibroma in point of absence of compression, encapsulation, remnants of normal structures, and reactivity with alcian blue ${ }^{5-8,14}$. Also, there is often a proliferation of blastimal cells and primitive glomerulo-tubular elements in the mesenchymal type of nephroblastoma ${ }^{4,8}$, our present case did not have these features. Therefore, we could differentiate it from the mesenchymal type.

Human CMN is said to be a particular type of nephroblastoma rarely having such hamartomatous properties as rhabdomyocytic differentiation, angioid forms, hematopoietic foci, cartilaginous foci, or dysplasic nephron constituents ${ }^{10,15,16}$. Additionally, human $\mathrm{CMN}$ can be classified by morphology into three major groups: classical (fibromatous), cellular, and combined (mixed) type ${ }^{10,16}$. The cellular type tends to have higher cellularity with many mitotic figures. The cellular and mixed types seem to be more malignant than the classical type. In our case, in spite of the infiltration to the adjacent nephrons, we concluded that the tumor belonged to the benign classical type on the basis of the above three human categories, because malignant features such as cytological atypia, high mitotic rate, focal hemorrhage, and necrosis were lacking. Additionally, the pattern of infiltration suggested that the tumor grew more or less harmoniously during fetal life as the cases in human ${ }^{14}$.

The present report is the first description of a spontaneous congenital mesoblastic nephroma in a young beagle dog undertaken by the use of both of ultrastructural and immunohistochemical investigations. From now on, more canine cases of CMN will need to be studied immunohistochemically and electromicroscopically in order to further clarify the pathognomonic features and pathema of CMN.

\section{References}

1. Hayes, $\mathrm{HM} \mathrm{J}_{\mathrm{r}}$ and Fraumeni, $\mathrm{FF} \mathrm{J}$ : Epidemiological features of canine renal neoplasms. Cancer Res 37 : 2553-2556, 1977.

2. Baskin, GB and Paoli, AD: Primary renal neoplasms of the dog. Vet Pathol 14: 591-605, 1977.

3. Lucke, VM and Kelly DF : Renal carcinoma in the dog. Vet Pathol 13 : 264-276, 1976.

4. Simpson, RM, Gliatto, JM, Casey HW, and Henk, WG : The histologic, ultrastructural, and immunohistochemical features of a blastema-predominant canine nephroblastoma. Vet Pathol $29:$ 250-253, 1992.

5. Diters, $\mathbf{R W}$ and Wells, $\mathbf{M}$ : Renal interstitial cell tumors in the dog. Vet Pathol 23 : 74-76, 1986.

6. Picut, CA and Valentine, BA : Renal fibroma in four dogs. Vet Pathol 22 : 422-423, 1985.

7. Splitter, GA, Rawlings, CA, and Casey HW : Renal hamartoma in a dog. Am J Vet Res 33: 273-275, 1972.

8. Takeda, T, Makita, T, Nakamura, N, and Horie, H : Congenital mesoblastic nephroma in a dog: a benign variant of nephroblastoma. Vet Pathol 26: 281-282, 1989.

9. Zwicker, GM and Cronin, NS : Naturally occurring renal neurofibroma in a laboratory beagle. Toxicol Pathol 20 : 112-114, 1992.

10. Pettinato, G, Manivel, JC, Wick, MR, and Dehner LP : Clinical and cellular (atypical) congenital mesoblastic nephroma. Hum Pathol 20 : 682-690, 1989.

11. Nadasdy, T, Roth, J, Johnson, DL, Bane, BL, Weinberg, A, Verani, R, and Silva, FG: Congenital mesoblastic nephroma : an immunohistochemical and lectin study. Hum Pathol 24 : 413-419, 1993.

12. Enzinger, FM and Weiss SW : Solitary neurofibroma and neurofibromatosis. In : Soft tissue tumor, 3rd ed., Enzynger, FM and Weiss, SW Eds, St. Louis: CV Mosby, 843-863, 1994.

13. Yamaguchi, S: A case of renal schowannoma. Acta Urol Jpn 36 : 55-58, 1990.

14. Beckwith, JB : Congenital mesoblastic nephroma. In : Renal pathology with clinical and functional correlations, Volume 2, Tisher, CC, and Brenner, BM Eds, Philadelphia J.B. Lippincott Company, 1452-1456, 1989.

15. Blande, RP: Congenital mesoblastic nephroma in infancy. Perspec Ped Pathol 1 : 227-250, 1973.

16. Shen, SC and Yunis EJ : A study of the cellularity and ultrastructure of congenital mesoblastic nephroma. Cancer 45 : 306-314, 1980. 